\title{
Drag, morphology and mechanical properties of three species of octocorals
}

\author{
Ming-Chao Lin, Chang-Feng Dai* \\ Institute of Oceanography, National Taiwan University, PO Box 23-13, Taipei, Taiwan \\ Received 10 January 1995; revised 20 October 1995; accepted 31 October 1995
}

\begin{abstract}
Drag force, morphology and mechanical properties of three Sarcophyton species, S. buitendijki Verseveldt, S. cinereum Tixier-Durivault and S. crassocaule Moser were studied. Among the three species, $S$. buitendijki has the highest flexibility and lowest stiffness that enable them to bend into a drag-reducing orientation by collapsing the colony and lying near the substratum at higher velocities. $S$. cinereum has intermediate flexibility and stiffness; deformation of the colony does not result in the reduction of drag forces, it resists drag forces by stiffness. Colonies of $S$. crassocaule have the highest stiffness which allows them to retain streamlining. They reduce drag forces by staying in the lower-velocity boundary layer. This study shows that the three sympatric Sarcophyton species possess different morphological and mechanical properties and they coexist in the same environment by adopting different strategies to reduce drag forces.
\end{abstract}

Keywords: Alcyonacea; Biomechanics; Drag; Morphology; Water flow

\section{Introduction}

Fluid flow is an important cnvironmental factor acting upon sessile organisms (Kochl, 1982a). These organisms depend on moving water to bring them food and to carry away wastes, but they also risk being dislodged or broken by fluid flow (Koehl, 1984; Denny et al., 1985; Denny, 1988). A fluid moving relative to an organism imposes mechanical forces upon that organism. These forces, which tend to carry the organism downstream, are known as drag forces (Wainwright et al., 1976; Vogel. 1981).

Drag force is an important factor influencing the morphology and mechanical

*Corresponding author. Tel.: +886-2-3916693. Fax: +886-2-3916693; e-mail: corallab@ccms.ntu.edu.tw 
properties of sessile organisms (Rees, 1972; Chamberlain and Graus, 1975; Velimirov, 1976). Sessile organisms, such as octocorals, require hydrodynamic adaptations to reduce the effect of drag forces (Wainwright and Dillon, 1969; Grigg, 1972; Jackson, 1979; Patterson, 1980). The morphology and behaviour of these animals also affect the flow patterns and drag forces they encounter (Sponaugle, 1991; Abelson et al., 1993; Dai and Lin, 1993).

Alcyonacean corals are among the most abundant sessile organisms on many IndoPacific coral reefs (Benayahu and Loya, 1977; Dinesen, 1983; Dai, 1993). They commonly exist on the reefs exposed to currents and storm disturbances (Dai, 1991). Hydrodynamic conditions may play an important role in determining the distribution of alcyonacean corals.

Alcyonacean corals exhibit remarkable plasticity with respect to colony shape and mechanical properties of tissues (Patterson, 1980; Koehl, 1982b). Sarcophyton species demonstrate a great variety in morphological and structural diversity (Verseveldt, 1982). However, the variations in morphology and mechanical properties of these organisms as a function of water movement are little investigated. We conducted a comparative assessment relating the morphology and mechanical properties of three Sarcophyton species to the drag forces they encountered under various flow velocities.

\section{Materials and methods}

\subsection{Specimen collection and acclimation}

Colonies of three Sarcophyton species, S. buitendijki Verseveldt, S. cinereum TixierDurivault and $S$. crassocaule Moser were collected from the coral reef in Nanwan Bay, southern Taiwan $\left(120^{\circ} 44^{\prime} \mathrm{E}, 21^{\circ} 57^{\prime} \mathrm{N}\right)$. Species identifications followed Verseveldt (1982). Colonies of $S$. cinereum and $S$. buitendijki are erect and funnel-shaped. The capitulum margin of the latter species is highly folded. Colonies of $S$. crassocaule are flat with a short stalk.

Coral colonies of diameter $0.12-0.15 \mathrm{~m}$ were collected from the field and transferred to an acclimation tank in which the temperature was maintained at $24^{\circ} \mathrm{C}$. The acclimation tank was furnished with two current generators which create consistent flow. These colonies were fed with resolvable food blocks (Reef Care, No. 134, Aquarium Pharmaceuticals). Three days were allowed for acclimation before the experiments.

A recirculating flow tank of capacity $75 \mathrm{l}(3.2 \mathrm{~m}$ long, $0.15 \mathrm{~m}$ wide, $0.2 \mathrm{~m}$ high) was made according to Leversee (1976). The tank was filled with 701 filtered seawater and a laboratory stirrer (Her-Cheng SC-VS35W) with a propeller $(0.14 \mathrm{~m}$ diameter) was used to generate water flow. The flow velocity was controlled by a solid-state motor control and measured with an electromagnetic current meter (Kenek, VM-401H). Detector (sensor part $\varnothing 8 \mathrm{~mm} \times 30 \mathrm{~mm}$ ) of the current meter was placed $0.15 \mathrm{~m}$ upstream from the colony. 


\subsection{Flume experiments}

During the experiment, a coral colony was transferred into the flow tank and fastened on an acrylic base. The base was supported by a tray filled with stainless steel balls on the surface to reduce friction. The acrylic base was connected to a suspended electronic balance (Yong-Ten HA-02) by a nylon line. When the coral colony experienced stress from the water flow, the acrylic base moved on the tray and transmitted the force to the suspended electronic balance via the nylon line. The drag forces induced by a coral colony at various flow velocities were measured with the balance. The drag forces were then standardized by dividing them by the initial projected colony area.

The coral was allowed $6 \mathrm{~h}$ for further acclimation before drag measurement and only colonies with fully expanded polyps were tested. Three colonies were tested for each species. Each colony was tested at flow velocities ranging from 0 to $0.35 \mathrm{~m} \mathrm{~s}^{-1}$ at an interval of $0.05 \mathrm{~m} \mathrm{~s}^{-1}$.

Colony profiles at various flow velocitics were photographed through the window of the tank using a camera. Since deflection of an organism in response to flowing water depends on its flexibility (Vogel, 1984), the flexibility of a coral colony is represented by the deflective angle of the colony at various flow velocities.

Projected colony areas perpendicular to the flow at various velocities were then photographed using an underwater camera (Nikonos-V) with a $20 \mathrm{~mm}$ lens. The photographs of projected colony area were traced and measured using a digitizer (Lab Visions LV-1) associated with a personal computer. Variations of colony area under various flow velocities were standardized by dividing the measured projected area by the initial projected colony area.

Drag coefficients of the three species were calculated from the drag measurements and projected colony areas, based on the equation:

$$
C_{\mathrm{D}}=2 D /\left(\rho S U^{2}\right)
$$

where $C_{\mathrm{D}}$ is drag coefficient, $D$ is drag force, $\rho$ is density of fluid, $S$ is projected colony area and $U$ is velocity (Vogel, 1981).

\subsection{Mechanical testing}

The coral colonies were anaesthetized overnight in a sea water $-20 \% \mathrm{MgSO}_{4} \cdot 7 \mathrm{H}_{2} \mathrm{O}$ solution mixture (1:1) until polyps did not contract when pinched with a forceps (Koehl, 1982b). Strips of tissue were cut from the stalk of coral colonies with a slicing machine (Omas VS250) and prepared for mechanical tests.

Strips of tissue were stretched in a mechanical test system (MTS 810) that simultaneously printed the force-extension diagram on a plotter (X-Y recorder, Yokogawa 3025). The strain rate was controlled in $\epsilon=0.01 \mathrm{~s}^{-1}$ (where $\epsilon=\Delta L / L_{\mathrm{o}} \cdot t, \Delta L$ is the variation of length of the specimen at time $t$, and $L_{\mathrm{o}}$ is the original length of the specimen). Stress $(\sigma)$ and extension ratio $(\lambda)$ were calculated according to $F / A$ ( $F$ is force and $A$ is cross-sectional area) and $\Delta L / L_{0}$. Plots of stress versus extension ratio 
were made. The slope of the straight portion of each stress-extension curve was taken to be the modulus of elasticity, a measure of stiffness (Koehl, 1982b).

\section{Results}

\subsection{Drag forces}

The drag forces encountered by colonies of the three species under various flow velocities showed different patterns (Fig. 1). The drag forces of Sarcophyton cinereum and $S$. crassocaule were basically proportional to the square of flow velocity. However, the drag forces of $S$. buitendijki showed two distinct trends with the breaking point appearing at $0.15 \mathrm{~m} \mathrm{~s}^{-1}$. Below this point, the drag forces increased rapidly with increasing flow velocities. While above this point, the drag forces increased slowly with flow velocities. The variation of drag force was also related to projected colony area and drag coefficient under various flow velocities.

The projected colony area of Sarcophyton crassocaule at various flow velocities remained roughly constant (Fig. 2). No significant difference was found between the mean colony area at a particular flow velocity and the initial colony area $(t=1.093$, $P>0.05$ ). The projected colony areas of $S$. buitendijki and $S$. cinereum increased with flow velocity initially, then reduced with increasing flow velocity. The upstream fringe

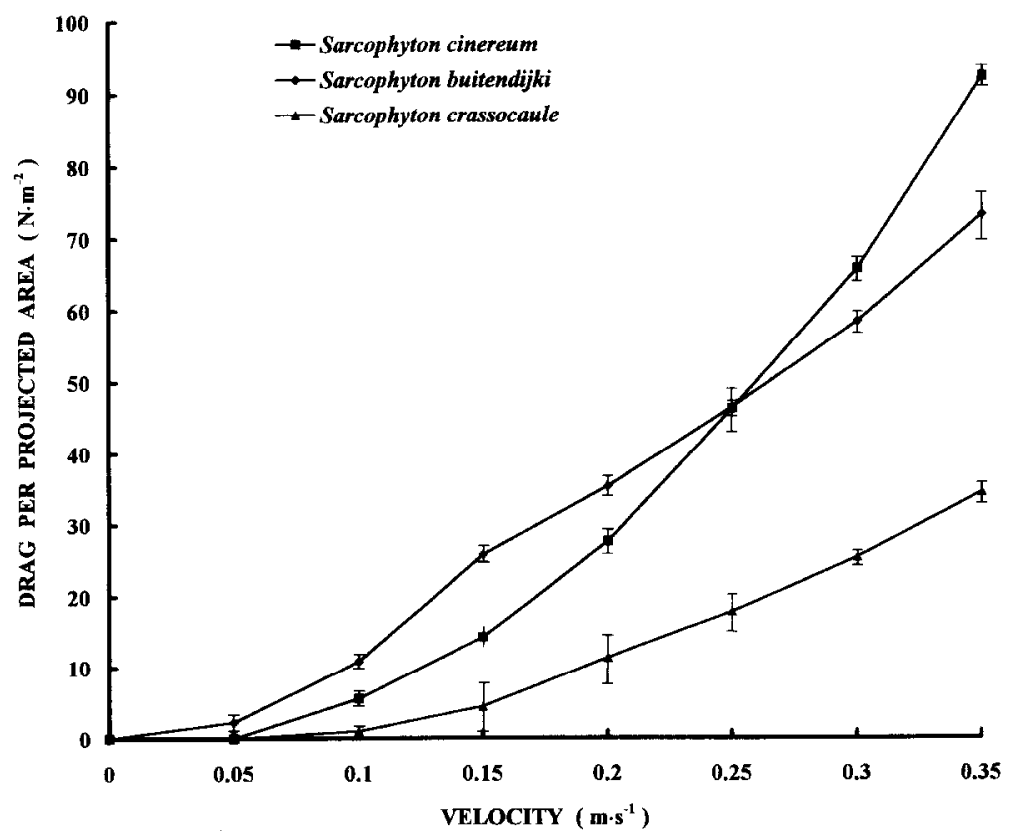

Fig. 1. Drag per projected area as a function of flow velocity for Sarcophyton cinereum, S. buitendijki and $S$. crassocaule. 


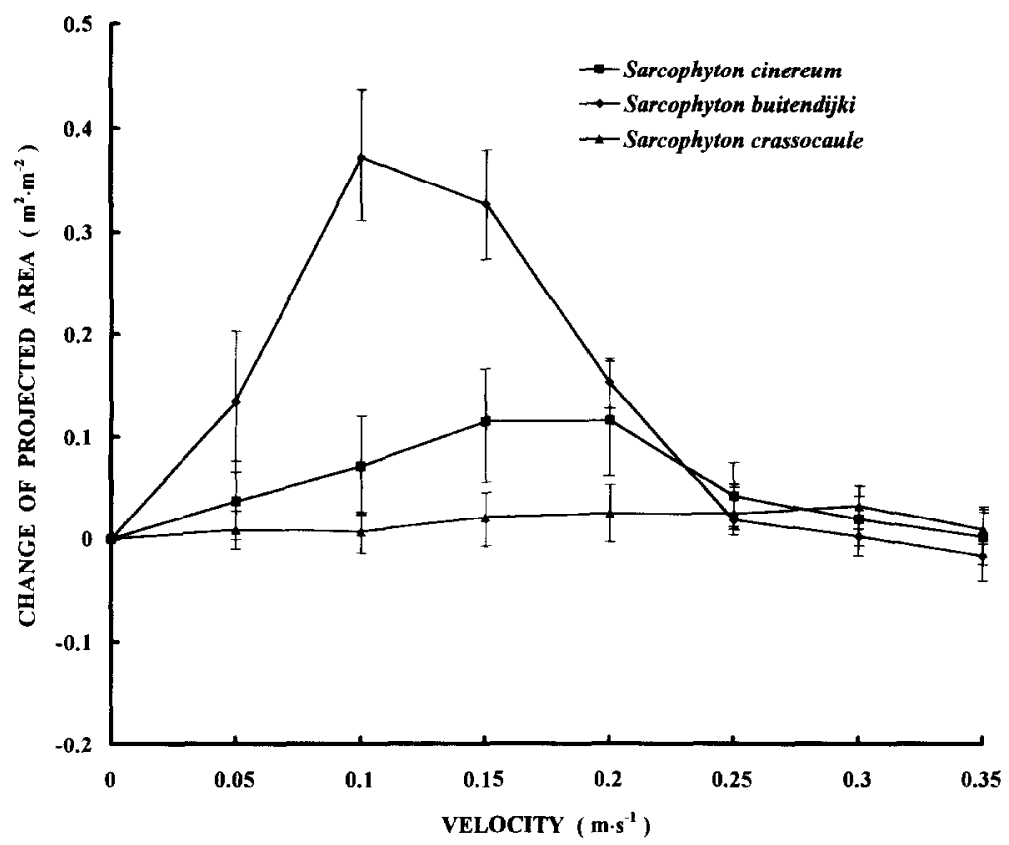

Fig. 2. Variation of projected area as a function of flow velocity for Sarcophyton cinereum, S. buitendijki and $S$. crassocaule.

of capitulum of $S$. buitendijki was lifted by flow and resulted in an increase of projected colony area, and the drag force increased rapidly from 0 to $0.1 \mathrm{~m} \mathrm{~s}^{-1}$. The capitulum clumped and the stalk tended to orient parallel to the flow, which resulted in a reduction of projected colony area, and the drag force increased slowly above $0.1 \mathrm{~m} \mathrm{~s}^{-1}$. The capitulum of $S$. cinereum showed no obvious variation with flow velocity, but the stalk was tilted with increasing flow velocity. The maximum projected colony area appeared during $0.15-0.2 \mathrm{~m} \mathrm{~s}^{-1}$.

Variation of drag coefficient with flow velocity is related to the body shape of an organism (Vogel, 1981). Sarcophyton crassocaule exhibited no significant variation of drag cocfficient with flow velocity (Fig. 3). The drag coefficient of S. cinereum increased with flow velocity (Fig. 3). The drag coefficient of $S$. buitendijki increased with flow velocity from 0 to $0.15 \mathrm{~m} \mathrm{~s}^{-1}$, then reduced by collapsing the colony into more compact streamlining at $>0.15 \mathrm{~m} \mathrm{~s}^{-1}$.

Morphological deformation of the three species at various flow velocities showed different patterns (Fig. 4). Sarcophyton crassocaule showed no obvious deflection at various flow velocities. The deflective angles of colony axes of $S$. buitendijki and $S$. cinereum increased with flow velocities, but the former deflected more readily than the latter. $S$. cinereum was tilted from 20 to $70^{\circ}$ in the direction of water movement with increasing flow velocity. $S$. buitendijki deflected rapidly from 0 to $0.15 \mathrm{~m} \mathrm{~s}^{-1}$, then slowly due to streamlining at flow velocities $>0.15 \mathrm{~m} \mathrm{~s}^{-1}$. The results showed that $S$. buitendijki is the most flexible of the three species. 


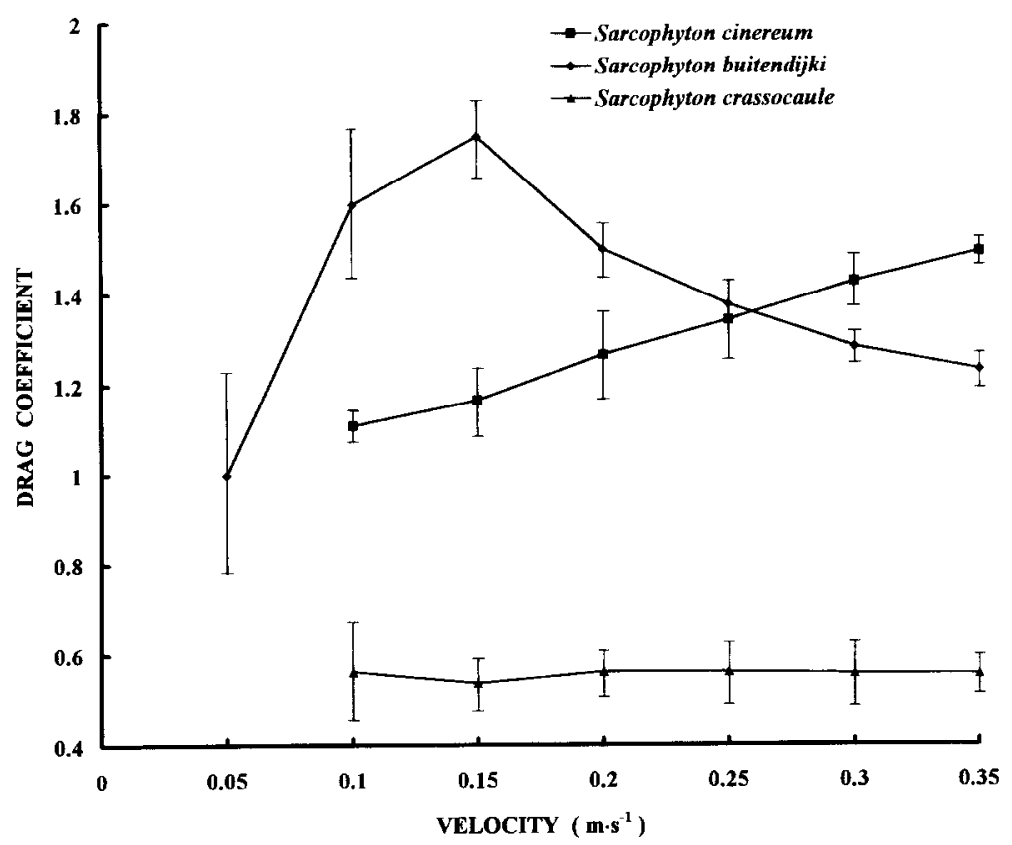

Fig. 3. Drag coefficient as a function of flow velocity for Sarcophyton cinereum, $S$. buitendijki and $S$. crassocaule.

\subsection{Tensile strength}

The stress-strain curves show that the stress of Sarcophyton crassocaule increased more rapidly with increasing strain than those of $S$. cinereum and $S$. buitendijki (Fig. 5). Hence the elastic modulus of $S$. crassocaule $\left(E=13.37 \pm 1.76 \mathrm{MN} \mathrm{m}^{-2}, n=3\right)$ is higher than those of $S$. cinereum $\left(E=8.50 \pm 1.18 \mathrm{MN} \mathrm{m}^{-2}, n=3\right)$ and $S$. buitendijki $(E=$ $3.47 \pm 0.79 \mathrm{MN} \mathrm{m}^{-2}, n=3$ ). Since tensile strength depends upon elastic modulus of the tissues, $S$. crassocaule has the highest stiffness, and $S$. buitendijki the lowest.

\section{Discussion}

The three Sarcophyton species revealed three different strategies to withstand drag force: flexibility, streamlining and stiffness. A flexible organism exposed to flow may minimize drag force by altering colony shape and reducing projected colony area (Vogel, 1984; Harvell and LaBarbera, 1985). The flexibility of Sarcophyton buitendijki colonies enables them to bend into a drag-reducing shape and orientation at higher velocities. The wake behind the colony is reduced and the drag coefficient is therefore reduced (Koehl, 1982a) as ambient flow tends to pass around the organism rather than to impinge on it (Wainwright and Koehl, 1976). The deformation or reorientation of an organism contributes to the variation of drag coefficient, and therefore, also contributes to the drag 


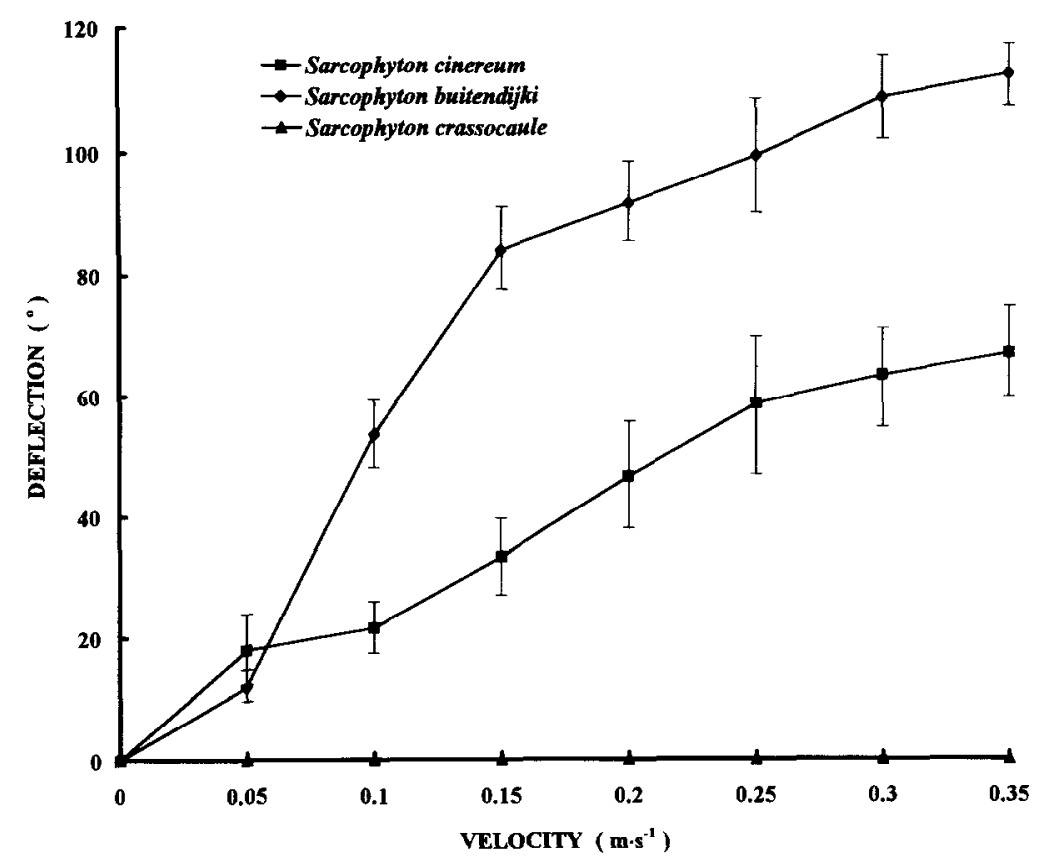

Fig. 4. Deflective angle of colony axis as a function of flow velocity for Sarcophyton cinereum, S. buitendijki and $S$. crassocaule.

forces experienced in flow (Sponaugle and LaBarbera, 1991; Dudgeon and Johnson, 1992). Flexibility acts to reduce the drag coefficient and the wake size behind the organism, thus the drag force can be reduced (Koehl, 1984).

Soft corals can minimize drag forces by lying within the boundary layer where the water velocities are lower than mainstream (Vogel, 1984). Colonies of Sarcophyton crassocaule are flat and they tend to live within the boundary layer. The flat colony also indicates that they are essentially streamlined. The high stiffness of $S$. crassocaule may allow them to retain the streamlining and to stay in the lower-velocity boundary layer.

Stiffness may also increase the capacity of an organism to withstand flow stresses (Koehl, 1979, 1982b; Vogel, 1988). Sarcophyton cinereum has intermediate flexibility and stiffness among the three species. Since the deformation of $S$. cinereum colonies results in no significant reduction of drag forces, this species may resist drags by stiffness rather than avoiding such forces by deformation.

Although both colonies of Sarcophyton buitendijki and $S$. cinereum are erect, they show different patterns in the relationship between drag forces and flow velocities. The drag force of $S$. cinereum increased with drag coefficient due to change in shape. A similar phenomenon was reported in two gorgonians by Sponaugle and LaBarbera (1991) where they suggested that a large reduction in the drag coefficient with increasing flow velocity that change in shape, rather than change in projected colony area, is primarily responsible for the reduction of drag force in a flexible colony. However, the flexibility of $S$. buitendijki colonies enables them to change shape readily. 


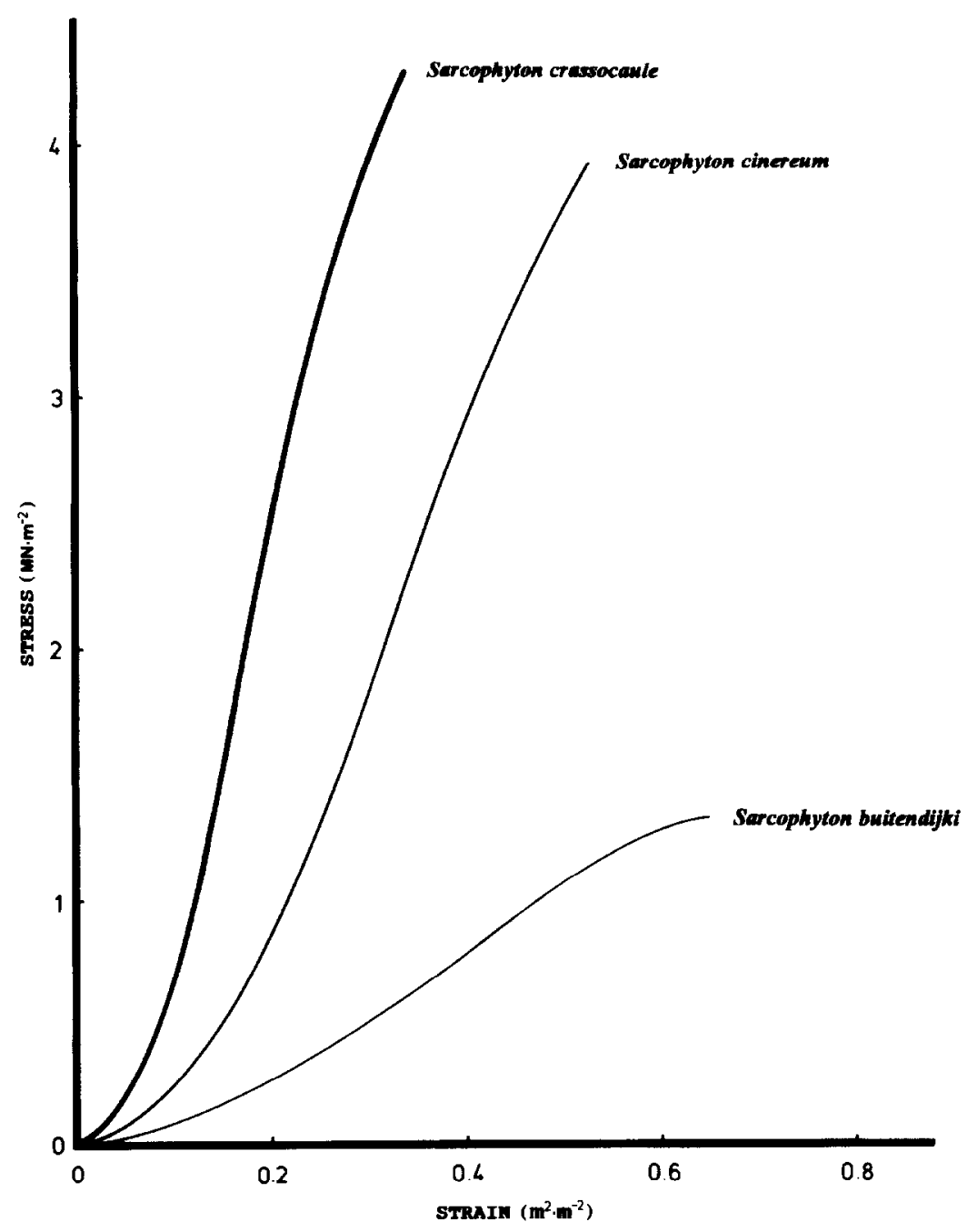

Fig. 5. Stress as a function of strain for the stalk tissue for Sarcophyton cinereum, S. buitendijki and $S$. crassocaule.

The drag force of $S$. buitendijki increased slowly whereas the projected colony area and drag coefficient reduced with flow velocity. The reduction in drag force of $S$. buitendijki is related to the reductions of projected colony area and drag coefficient due to change in shape.

The shape, size, flexibility, texture and behaviour of an organism affect the drag forces it encounters (Koehl, 1982a; Vogel, 1981). The three sympatric Sarcophyton species experience similar flow stresses, but they possess different morphological, mechanical and behavioural properties to reduce drag forces. $S$. cinereum likely reduces drag force by stiffness, $S$. buitendijki by flexibility and $S$. crassocaule by streamlining. 
Hence various species coexisting in a same environment may adopt different strategies to reduce drag forces.

\section{Acknowledgments}

We thank Mr. T.-S. Chen, Y.-C. Tsay and T.-Y. Fan for their assistance in specimen collection. We are also indebted to the Kenting Marine Biological Research Station of National Sun Yat-Sen University for providing lab space, and to Mr. T.J. Wei for his assistance during the experiments. The earlier draft of this manuscript benefitted from the comments of Dr. D.R. Good and Mr. T.T. Lynch. We are grateful to Dr. B.L. Bayne and one anonymous reviewer for their critical reading. This study was supported by National Science Council, ROC (NSC 81-0418-B-002A-504-BH).

\section{References}

Abelson, A., T. Miloh and Y. Loya, 1993. Flow patterns induced by substrata and body morphologies of benthic organisms, and their roles in determining availability of food particles. Limnol. Oceanogr., Vol. 38, pp. 1116-1124.

Benayahu, Y. and Y. Loya, 1977. Space partitioning by stony corals, soft corals and benthic algae on the coral reef of the northern Gulf of Eilat (Red Sea). Helgol. Wiss. Meeresunters., Vol. 30, pp. 362-382.

Chamberlain, J.A. and R.R. Graus, 1975. Water flow and hydromechanical adaptations of branched reef corals. Bull. Mar. Sci., Vol. 25, pp. 112-125.

Dai, C.-F., 1991. Distribution and adaptive strategies of alcyonacean corals in Nanwan Bay, Taiwan. Hydrobiologia, Vol. 216/217, pp. 241-246.

Dai, C.F., 1993. Patterns of coral distribution and henthic space partitioning on the fringing reefs of southern Taiwan. Mar. Ecol., Vol. 14, pp. 183-204.

Dai, C.-F. and M.-C. Lin, 1993. The effects of flow on feeding of three gorgonians from southern Taiwan. $J$. Exp. Mar. Biol. Ecol., Vol. 173, pp. 57-69.

Denny, M.W., 1988. Biology and the mechanics of the wave-swept environment. Princeton University Press, Princeton, NJ, $320 \mathrm{pp}$.

Denny, M.W., T.L. Daniel and M.A.R. Koehl, 1985. Mechanical limits to size in wave-swept organisms. Ecol. Monogr., Vol. 55, pp. 69-102.

Dinesen, Z.D., 1983. Patterns in the distribution of soft corals across the Central Great Barrier Reef. Coral Reefs, Vol. 1, pp. 229-236.

Dudgeon, S.R. and A.S. Johnson, 1992. Thick vs. thin: thallus morphology and tissue mechanics influence differential drag and dislodgment of two co-dominant seaweeds. J. Exp. Mar. Biol. Ecol., Vol, 165, pp. $23-43$

Grigg, R.W., 1972. Orientation and growth form of sea fans. Limnol. Oceanogr. 17, pp. 85-192.

Harvell, C.D. and M. LaBarbera, 1985. Flexibility: a mechanism for control of local velocities in hydroid colonies. Biol. Bull., Vol. 168, pp. 312-320.

Jackson, J.B.C., 1979. Morphological strategies of sessile animals. In, Biology and Systematics of colonial organisms, edited by G. Larwood and B.R. Rosen, Academic Press, London, pp. 499-556.

Koehl, M.A.R., 1979. Stiffness or extensibility of intertidal algae: a comparative study of modes of withstanding wave action. J. Biomech., Vol. 12, pp. 634.

Koehl, M.A.R., 1982a. The interaction of moving water and sessile organisms. Sci. Am., Vol. 247, pp. $110-120$.

Koehl, M.A.R., 1982b. Mechanical design of spicule-reinforced connective tissue: stiffness. J. Exp. Biol., Vol. 98, pp. $239-267$. 
Koehl, M.A.R., 1984. How do benthic organisms withstand moving water? Am. Zool., Vol. 24, pp. 57-70.

Leversee, G.J., 1976. Flow and feeding in fan-shaped colonies of the Gorgonian coral, Leptogorgia. Biol. Bull., Vol. 151, pp. 344-356.

Patterson, M.R., 1980. Hydromechanical adaptation in Alcyonium sidereum (Octocorallia). In, Biofluid mechanics, edited by D.J. Schneck, Plenum Press, New York, NY, pp. 183-201.

Rees, J.T., 1972. The effect of current on growth form in an octocoral. J. Exp. Mar. Biol. Ecol, Vol. 10, pp. $115-123$.

Sponaugle, S., 1991. Flow patterns and velocities around a suspension-feeding gorgonian polyp: evidence from physical models. J. Exp. Mar. Biol. Ecol., Vol. 148, pp. 135-145.

Sponaugle, S. and M. LaBarbera, 1991. Drag-induced deformation: a functional feeding strategy in two species of gorgonians. J. Exp. Mar. Biol. Ecol., Vol. 148, pp. 121-134.

Velimirov, B., 1976. Variation in growth forms of Eunicella cavolinii Koch (Octocorallia) related to intensity of water movement. J. Exp. Mar. Biol. Ecol., Vol. 21, pp. 109-117.

Verseveldt, J., 1982. A revision of the genus Sarcophyton Lesson (Octocorallia, Alcyonacea). Zool. Verhand., Vol. $192,115 \mathrm{pp}$.

Vogel, S., 1981. Life in moving fluids: The physical biology of flow. Princeton University Press, Princeton, NJ, $352 \mathrm{pp}$.

Vogel, S., 1984. Drag and flexibility in sessile organisms. Am. Zool., Vol. 24, pp. 37-44.

Vogel, S., 1988. Life's devices: The physical world of animals and plants. Princeton University Press, Princeton, NJ, $367 \mathrm{pp}$.

Wainwright, S.A. and J.R. Dillon, 1969. On the orientation of sea fans. Biol. Bull., Vol. 136, pp. 130-139.

Wainwright, S.A., W.D. Biggs, J.D. Currey and J.M. Gosline, 1976. Mechanical design in organisms. Edward Arnold, London, $423 \mathrm{pp}$.

Wainwright, S.A. and M.A. Koehl, 1976. The nature of flow and the reaction of benthic cnidaria to it. In, Coelenterate ecology and behaviour, edited by G.O. Mackie. Plenum Press, New York, NY, pp. 5-28. 